PETER LITTLEJOHNS

Professor of public health ${ }^{3}$

\section{JUDITH RICHARDSON}

Associate director ${ }^{4}$

ALISTAIR ROBERTSON

Solicitor in healthcare, regulatory and public

${ }^{1}$ The Honourable Society of Lincoln's Inn, London, UK; ${ }^{2} D A C$ Beachcroft LLP, London, UK; ${ }^{3}$ Kings College London, UK; ${ }^{4}$ Centre for Clinical Practice National Institute for Health and Clinical Excellence, London, UK

\section{The impact of consultant-delivered multidisciplinary inpatient medical care on patient outcomes}

Editor - We read with interest the article by Fielding et al which assessed the impact of consultant-led multidisciplinary team (MDT)-delivered care on length of stay ( Clin Med August 2013 p344-8). Taken together with the earlier study by Ahmad et $a l^{1}$ there appears to be mounting support that increasing consultant-delivered ward rounds is associated with shorter length of stay. However, at our own institution we found that the introduction of two extra consultant 'winter pressure' ward rounds by the respiratory and general internal medicine (GIM) teams was associated with only a very modest saving in average length of stay when compared to the non-respiratory/GIM teams, who continued with two formal ward rounds per week (Table 1). Furthermore, an earlier start time of 8am did not appear to influence the time of TTO ('to take out' prescription) printing or the time of discharge.

While the data presented by Fielding et al are encouraging, we urge caution before widespread implementation of daily consultant- delivered care. As stated in the conclusion, their study was not a randomised controlled trial (RCT) and is open to considerable selection bias. Furthermore, they do not include a formal health economic analysis in their report, nor do they comment on the experience of the consultants concerned in terms of the sustainability of such high intensity work.

Despite the strongly worded conclusion of the Academy of Royal Colleges report ${ }^{2}$ recommending daily consultant-delivered care, to our knowledge there have been no RCTs performed in this area. The cost of employing sufficient consultants to deliver a consultant-led ward service will be substantial and persuading new consultants to sign up to delivering care without trainees will be challenging. While we support the concept of early and regular patient access to senior clinical decision makers, we advocate the collection of more robust data before the widespread introduction of daily consultant delivered care on general medical wards.

\section{References}

1 Ahmad A, Purewal TS, Sharma D, Weston PJ. The impact of twice-daily consultant ward rounds on the length of stay in two general medical wards. Clin Med 2011;11:524-8.

2 Academy of Medical Royal Colleges. The benefits of consultant-delivered care. London: Academy of Royal Colleges, 2012. aomrc.org.uk/component/docman/doc_ download/9450-the-benefits-of-consultantdelivered-care.html [Accessed 27 September 2013].

\section{IAN WOOLHOUSE}

Clinical service lead respiratory medicine

JONATHAN TREML

Clinical service lead geriatric medicine Queen Elizabeth Hospital Birmingham NHS Foundation Trust, Birmingham, UK

\section{Table 1. Impact of additional ward rounds and 8am start.}

\begin{tabular}{lllllll} 
& \multicolumn{2}{l}{$\begin{array}{l}\text { Average length of stay } \\
\text { (median (IQR) days) }\end{array}$} & $\begin{array}{l}\text { TTO printed before } \\
\text { 1pm (\%) }\end{array}$ & $\begin{array}{l}\text { Discharged before 1pm } \\
\text { (\%) }\end{array}$ \\
& $\begin{array}{l}\text { Four rounds } \\
\text { at 8am }\end{array}$ & $\begin{array}{l}\text { Standard } \\
\text { care }\end{array}$ & $\begin{array}{l}\text { Four rounds } \\
\text { at 8am }\end{array}$ & $\begin{array}{l}\text { Standard } \\
\text { care }\end{array}$ & $\begin{array}{l}\text { Four rounds } \\
\text { at 8am }\end{array}$ & $\begin{array}{l}\text { Standard } \\
\text { care }\end{array}$ \\
Pre-intervention* & $7.0(9.0)$ & $9.0(16)$ & 29.5 & 27.0 & 16.8 & 19.9 \\
Post-intervention* $^{*}$ & $7.0(8.0)$ & $10.0(21)$ & 32.6 & 29.3 & 18.0 & 20.2 \\
p-value $^{\dagger}$ & ns & 0.012 & NS & NS & NS & NS \\
\hline
\end{tabular}

$\mathrm{IQR}=$ inter-quartile range; NS $=$ not significant; $\mathrm{TTO}=$ to take out [discharge prescription]. ${ }^{*}$ Intervention = two additional ward rounds and 8am start.

${ }^{\dagger}$ Mann-Whitney U test

\section{A trainee's guide to surviving ePortfolio}

Editor - This is a follow up to Dr King's paper on the ePortfolio (Clin Med August 2013 pp 367-9). The Foundation Programme, workplace assessments and local faculty groups (foundation process) were implemented to accelerate foundation doctors' progression to expertise sufficient for full registration with the General Medical Council (GMC) and then into higher training. Vance et al reported trainees' considerable dissatisfaction with the processes. ${ }^{1}$ In the August edition of Clinical Medicine, Dr King wrote 'whether or not you like online portfolio systems, ePortfolio seems here to stay as a tool for assessment and advancement?. I believe the ePortfolio system may require swift changes to make it 'fit for purpose'.

In July 2013 I ran an online survey promoted on Twitter, which attracted responses from 36 consultant supervisors and 88 current foundation year (FY) doctors (32 FY1, 56 FY2). $75 \%$ of supervisors and $58 \%$ of trainees were not confident that the foundation process was 'fit for purpose' in supporting and accelerating training. $75 \%$ of supervisors were not confident that the process provides valid information to recommend full GMC registration at the end of FY1 or progression into higher training from FY2, a view shared by $62 \%$ of trainees. Only $33 \%$ of supervisors and $36 \%$ of trainees found the ePortfolio easy to use. $67 \%$ of supervisors felt irritation or dread when asked to complete an online assessment. 31\% of supervisors had not read any of the foundation curriculum, whereas $30 \%$ of trainees had read all and $65 \%$ some of the curriculum.

This was a small survey and participants were probably sceptical. However, the results mirror Vance et als findings. Full registration with the GMC is a weighty matter, as is assessment of FY2 to progress into higher training. Supervisors, trainees and the public must have confidence the processes are 'fit for purpose'. Swift changes are required to restore supervisors' and trainees' confidence in the foundation training process.

GORDON CALDWELL

Consultant physician and clinical tutor

Worthing Hospital, Western Sussex Hospitals NHS Foundation Trust, Worthing,

UK 